\title{
Grafitea en ELE
}

\section{LORENA GARCÍA SAIZ}

Instituto Baleares

logarsa@hotmail.com

\begin{abstract}
Resumen: Un elemento clave para favorecer la comunicación entre nativos y estudiantes de ELE es, por un lado, el dominio del contexto comunicativo y, por el otro, la adquisición de vocabulario. La propuesta presentada trabaja estos aspectos teniendo como hilo conductor el grafiti. Así, alumnado inmigrante de nivel A2 trabaja conjuntamente con estudiantes locales en un centro de secundaria para mejorar su comprensión y expresión oral y escrita, ampliar vocabulario en diversos campos semánticos, entender el papel de la metáfora y aplicar tipología textual diversa. Esto les sirve no solo para analizar grafitis de la ciudad, sino de su barrio. Como producto final, se invita a que cada pareja haga su propio grafiti acorde a una temática designada y se intercambie, para que otros estudiantes los describan e interpreten, con lo que se contrasta el significado otorgado por los creadores, frente al de los alumnos espectadores.
\end{abstract}

Palabras clave: comunicación, grafiti, metáfora, tipología textual.

\section{Let's do grafitti in ELE!}

Abstract: A key element in order to improve the communication between natives and ELE students is, on the one hand, the domain of the communicative context and, on the other, the acquisition of vocabulary. This didactical unit works these aspects with graffiti as a conductive thread. Thus, level A2 ELE students work together with local learners in a secondary school to improve their oral and written comprehension and expression, to broaden vocabulary in various semantic fields, to understand the role of metaphor and to apply different textual typologies. These aspects serve them not only to analyze graffiti of the city, but of their neighborhood. As a final product, each couple is invited to make their own graffiti according to a designated theme and be exchanged, so that other students describe and interpret them, thus contrasting the meaning given by the creators, compared to the spectators students.

Key words: communication, grafitti, metaphor, textual typology.

\section{Marco teórico}

El fomento de la relación entre nativos y estudiantado de ELE es clave para generar un marco comunicativo más significativo. Además, en el caso del alumnado que viene en edad de escolarización obligatoria a vivir a nuestro país, es fundamental que también se generen situaciones donde se cree un marco de intercambio no sólo lingüístico sino social, algo que los y las docentes no deben perder de vista, con el objetivo de garantizar la mejor integración posible. 
Esto se puede hacer generando situaciones en las que, a través de los contenidos, las actividades y metodologías propuestas se fomenten tanto los objetivos lingüísticos y comunicativos como los sociales y culturales.

Como muestra, este artículo presenta una unidad didáctica trabajada en $4^{\circ}$ de ESO en un instituto de la ciudad de Valencia. Este grupo presentaba una tipología especial. Concretamente, pese a ser un curso pequeño -compuesto por 14 estudiantes- el $40 \%$ procedía de países de habla no castellana y se había incorporado al sistema educativo español entre ese curso y el anterior.

Con este contexto, desde la materia de Lengua y Literatura Castellana se decidió trabajar aspectos como el aumento de vocabulario, el uso de la tipología textual o elementos abstractos como las metáforas haciendo uso de elementos cercanos a sus intereses como son los grafitis que, en definitiva, no dejan de ser metáforas visuales o mecanismos que permiten entender, mediante la cognición humana, conceptos abstractos y complejos mediante otros más concretos y sencillos.

Así, la metáfora «impregna la vida cotidiana, no solamente el lenguaje, sino también el pensamiento y la acción. Nuestro sistema conceptual ordinario, en términos del cual pensamos y actuamos, es fundamentalmente de naturaleza metafórica» (Lakoff y Johnson, 1998: 39).

Por tanto, a través de la experiencia se asocia a una imagen una serie de estructuras cognitivas que permite valorar, seleccionar, estructurar y entender el mundo dentro de unos referentes culturales y que, al mismo tiempo, sirven para enriquecer, ampliar, crear y materializar nuestra manera de pensar y de actuar.

De este modo, con el trabajo de la metáfora, el estudiantado aborda el proceso de reajuste entre significante y significado, desarrolla la agudeza y el entendimiento de la ironía, y comprende y aplica recursos estéticos, estilísticos y literarios. Además, puede ver cómo, a través del grafiti, se busca romper los moldes convencionales e imprimir un carácter especial a la expresión.

Con esta unidad, también se incide en la competencia comunicativa, basada en las necesidades comunicativas del estudiantado, unas interacciones significativas y realistas, las habilidades que ya tienen en su primera lengua y la interdisciplinariedad. Por tanto, se centra tanto en el conocimiento como en la habilidad para su uso cuando participa en una comunicación real donde, tal y como señala Canale (1995: 66)

El conocimiento hace referencia a lo que uno sabe (consciente o inconscientemente) sobre el lenguaje y sobre otros aspectos del uso comunicativo del lenguaje; la habilidad hace referencia a lo bien o mal que se utiliza ese conocimiento en la comunicación real

Por otra parte, se trabajan las características y estructuras del texto, entendido como «el producto de un acto lingüístico, o de una serie de actos lingüísticos conexos, de una persona determinada en una situación concreta» (Casado Velarde, 1998: 55).

Siguiendo la tipología textual de Werlich (en Loureda, 2003: 62-63),que tiene en cuenta los criterios de contexto extralingüístico y las estructuras de las oraciones, la unidad didáctica aborda el texto descriptivo -que usa el verbo ser o equivalente en presente, atemporal o neutro, y el imperfecto, donde abunda los adverbios de lugar y el referente es un agente $\mathrm{u}$ objetos en el espacio-; el expositivo -con el predominio del verbo ser o 
similares con predicado nominal o combinado con un objeto directo, principalmente usado en presente (con temporalidad neutra), con el que se analizan o sintetizan ideas y conceptos sobre un tema-; y el argumentativo, que usa la estructura con el verbo ser, en afirmativo o negativo, con predicado nominal y principalmente en presente. El referente es la relación de ideas o conceptos, ya que se quiere demostrar algo.

Por otro lado, también desarrolla elementos de la expresión escrita, claves para su posterior aplicación en el plano de la oralidad. Para ello, a la hora de aprender a producir textos escritos, «se debe desarrollar las fases de planificación, textualización y revisión de los mismos que se aplican con mayor o menor rigurosidad en función del nivel y dominio que tenga el estudiante, en este caso, de ELE» (Cassany, 2005: 46). Hay que destacar que esta experiencia en secundaria combina alumnado nativo y extranjero, por lo que el primero ayuda al segundo a que se desarrollen de manera más coherente los procesos cognitivos que se aplican en la escritura.

De acuerdo con el Plan Curricular del Instituto Cervantes (PCIC), esta unidad didáctica trabaja de manera general tácticas y estrategias pragmáticas, géneros discursivos $\mathrm{y}$ productos textuales, nociones generales y específicas, los referentes culturales, los saberes y comportamientos socioculturales y las habilidades y actitudes interculturales. Por otro lado, los contenidos que trata -dirigidos a alumnado de $4^{\circ}$ de Educación Secundario-Obligatoria (ESO)- se ubican dentro de la Ley Orgánica 8/2013, de 9 de diciembre, para la mejora de la calidad educativa (LOMCE) en el apartado Conocimientos de la lengua. Concretamente, se recoge dentro de los bloques de tipología textual y recursos literarios.

Los objetivos generales de esta unidad didáctica se centran en desarrollar la compresión y expresión oral y escrita acorde al contexto comunicativo; argumentar de manera clara y concisa; promover la tolerancia, desarrollar la conciencia crítica y trabajar la interacción y la mediación.

Los objetivos específicos son trabajar la estructura, características y finalidad de los textos descriptivo, expositivo y argumentativo; interpretar y construir metáforas $\mathrm{y}$ comparaciones; potenciar el aumento de vocabulario con fines objetivos y/o subjetivos, principalmente los adjetivos (explicativos y especificativos) y adverbios; conocer los símbolos y su significado en la cultura de acogida y acercarse a elementos propios de la cultura urbana como los grafitis.

En cuanto a las competencias generales, se abordan el conocimiento sociocultural, la consciencia intercultural y la competencia existencial. Respecto a las competencias comunicativas de la lengua, se tratan principalmente la lingüística (léxica y semántica), sociolingüística y pragmática.

El método de trabajo combina actividades en parejas y pequeños grupos y puesta en común en gran grupo. El docente en todo momento resuelve dudas tras las explicaciones y la resolución de ejercicios y, al inicio de cada sesión, recapitula los contenidos tratados antes. Además, se trabajan las destrezas de compresión y expresión oral y escrita, la interacción y la mediación.

En cuanto a la evaluación, los criterios que se deben tener en cuenta son la observación diaria del docente hacia el alumnado, ya que es clave mientras realiza actividades para consolidar los contenidos. Finalmente, hay una evaluación por parte del enseñante tanto de la situación comunicativa que las parejas representan como del producto final -el grafiti 
que han creado acorde a la temática designada-, a la que se añade una coevaluación entre el alumnado, todo ello mediante el uso de rúbricas. Los aspectos que se valoran son la aplicación de estructuras propias de textos descriptivos y argumentativos-expositivos y su organización, el vocabulario usado, el trabajo cooperativo y la interacción.

\section{Desarrollo de la unidad didáctica}

La propuesta didáctica abordó la metáfora y las tipologías textuales mediante su acercamiento al mundo del grafiti, un elemento característico de la cultura urbana y con el que los y las adolescentes están familiarizados, ya que en su contexto cercano -el barrio del Grao-Canyamelar de Valencia- conviven con este tipo de manifestaciones artísticas. Así, a través de estas realidades próximas se buscaba trabajar de forma cooperativa en el desarrollo de una serie de actividades guiadas que les condujera, en primer lugar, a conocer más a fondo las características de los grafitis para, posteriormente, pasar a analizarlos.

Para ello, alumnado local e inmigrante -esté último, con un nivel A2- que compartía aula adquirió y consolidó lenguaje específico para proceder a describir diversos grafitis y, posteriormente, analizar su significado $-\mathrm{y}$, por ende, las metáforas visuales que albergaban- con el desarrollo de textos expositivos-argumentativos.

Finalmente, el estudiantado participante también desarrolló su parte creativa, con la creación por parejas de un producto final, consistente en diseñar y dibujar un grafiti relacionado con una temática específica, que posteriormente fueron presentados al resto del aula, para su posterior análisis e intercambio de opiniones y valoraciones. Así, se buscaba aplicar el uso del vocabulario adquirido, la elaboración de metáforas y la producción oral de textos que combinar lo descriptivo, expositivo y argumentativo, que se había trabajado en sesiones anteriores.

La primera sesión se inició con una lluvia de ideas sobre el origen del grafiti, el porqué de su aparición y sus características, seguido del visionado de vídeos ilustrativos.

Posteriormente, y por parejas mixtas (alumnado local e inmigrante), debían ubicar un listado de expresiones, relacionados con aspectos que se podían abordar en el análisis y descripción de un grafiti, en su correspondiente campo léxico. Concretamente, situaban en las áreas color, forma, tamaño, acciones y elementos que acompañan al grafiti las siguientes expresiones:

(1) Rojo, personas, delante, rugoso, denunciar, primer plano, color, vivo, animales, blanco y negro, detrás, al fondo, a un lado, destacar, presentar, objetos, plantas, difuminado

Por tanto, se trabajaban diversas categorías de palabras tales como adjetivos, verbos, sustantivos o adverbios. A continuación, continuaban usando las mismas categorías para buscar palabras que les ayudaran a describir grafitis de artistas famosos que trabajan en Valencia, extraído de una web que los presenta ${ }^{1}$.

En la segunda sesión, se abordó la metáfora y la creación de significado. Para ello, el alumnado conoció algunas de las obras más destacadas de Bansky ${ }^{2}$, sobre las que tuvieron

\footnotetext{
${ }^{1} \mathrm{http}: / /$ meraviglia.es/los-grafiteros-mas-destacados-de-valencia/

$2 \mathrm{http}$ ://www.banksy.co.uk/
} 
que extraer, por un lado, el significado que quería transmitir y, por el otro, los elementos con los que quería concebir dicho significado. Posteriormente, se procedió a un ejercicio libre de creación de metáforas y asignación de significados, tal y como se muestra en la imagen 1.

\section{CREACIÓN DE METÁFORAS}

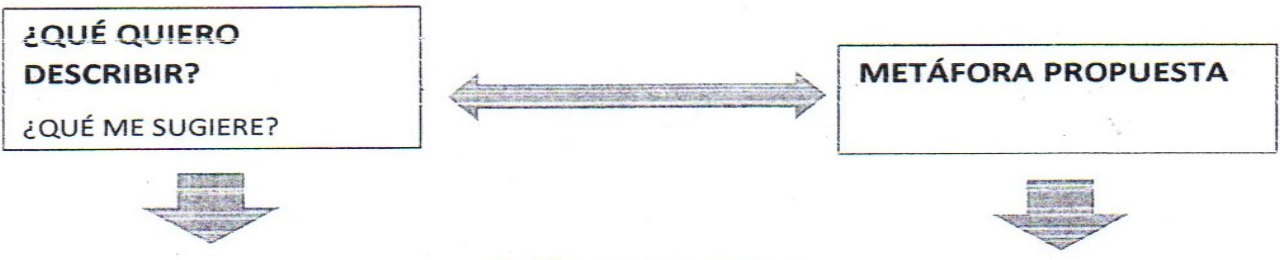

QUÉ ME SUGIERE

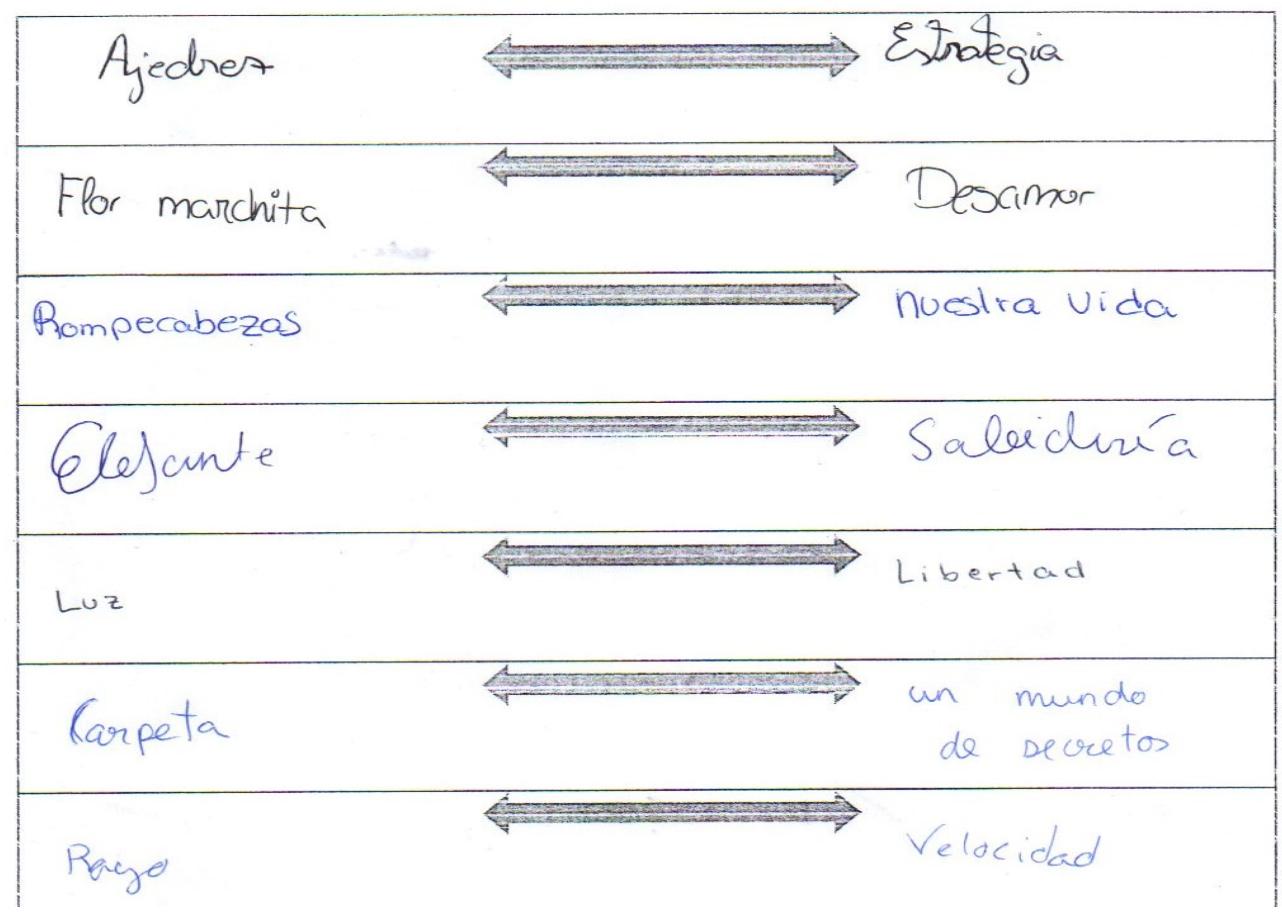

Imagen 1. El alumnado asoció elementos a significados creando metáforas

En las dos actividades se trabajó primero por parejas mixtas y, posteriormente, se pusieron en común tanto las creaciones metafóricas como las interpretaciones de la obra del famoso grafitero británico.

En las dos siguientes sesiones las parejas presentaron ante el resto del aula una serie de grafitis que habían fotografiado en el barrio para, al mismo tiempo, describirlos y exponer y argumentar el significado que otorgaban a estas composiciones artísticas urbanas. Para ello, el docente les proporcionó un guion que debían cumplimentar, en el que usaban algunas de las expresiones que habían aprendido e interiorizado en las anteriores jornadas, tal y como se muestra en la imagen 2 y 3 . 


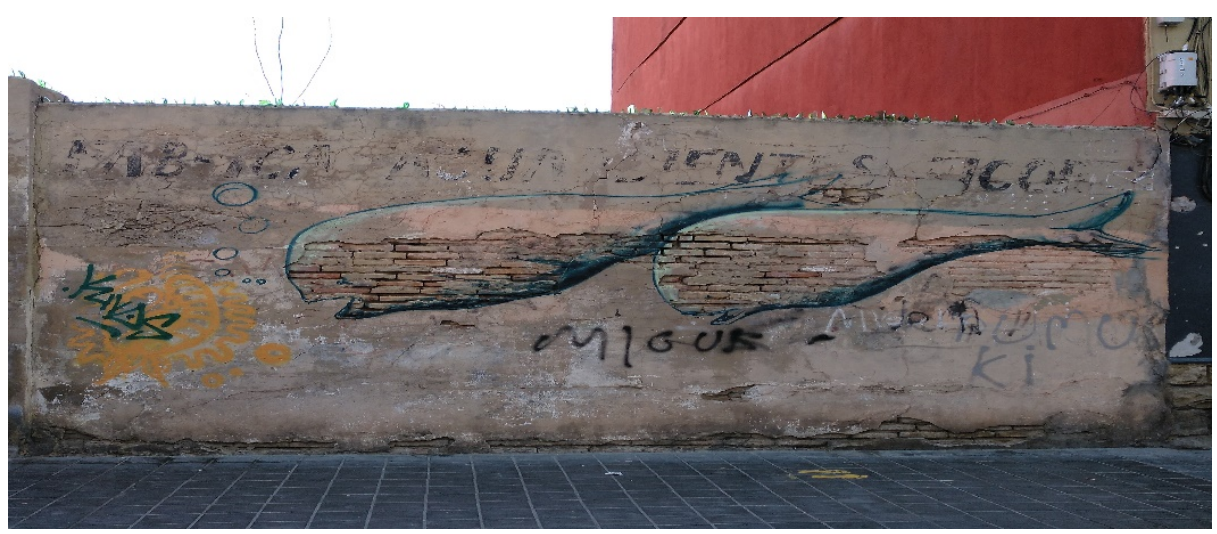

Imagen 2. Grafiti del barrio analizado acorde a imagen 3, según guion facilitado por el docente

\section{PROPUESTA DE GUIÓN GRAFITERO}

- Nomise GRAFITI: Cl mar ballemo

- Este grafitise encuentra en la calle Vicente Brull

- Esta dibujado en paned rota car ladiull

- Elsla artista es no pane finma

- El grafiti consiste en dos hallena que nedar

- Sutamañoes gremde

- Predominan ei/los color/es sueve cálido

- Tiene forma/s redindar

- Los elementos que aparecen son ballena sontan

- En primerplano balleman

- En segundo plano ledvilla utos

- Tiene más importancia amimala

- Asuizquierda mada

- Asuderecha mada

- Viene acompañado de las siguientes palabras o formas entán bronon

- Pensamos que el grafiti trata de cuidar amimale. porque

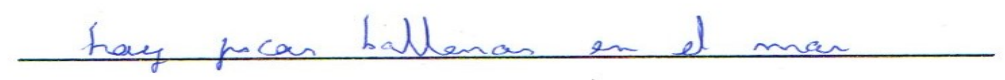

Imagen 3. Ejemplo del guion aplicado al análisis del grafiti de la imagen 2 
Finalmente, se dedicaron dos sesiones más para la realización del producto final. Concretamente, la docente repartió una serie de temas genéricos entre las parejas mixtas -como la protección del medioambiente, la alimentación saludable, la mujer como objeto sexual, la paz, la pobreza y el cuidado animal- para que realizaran una composición artística libre a modo de grafiti, que recogiera un mensaje con relación al tópico abordado. La primera sesión se centró en su discusión, preparación y elaboración y la segunda, en la presentación de la obra.

En cuanto a la presentación del grafiti, la dinámica empezó con un intercambio por parejas de las creaciones realizadas, de modo que debían interpretar la/s metáfora/s existentes y, a continuación, explicarlas y justificarlas. Más tarde, la unidad se completó con la presentación genérica al gran grupo de todas las creaciones, con la recogida de interpretaciones de dichas obras. En la imagen 4 -que aparece como anexo de este artículo en su parte final-, se puede ver un ejemplo de la labor realizada alrededor de la temática de "la mujer como objeto sexual", con imágenes de las manos de una mujer atadas con cadenas, con la boca tapada y una reflexión.

De este modo, se comprobó como de una manera significativa y atractiva para el estudiantado, se logró la asunción de contenidos trabajados y objetivos propuestos mediante la expresión y compresión oral y escrita de elementos abstractos y complejos como las metáforas visuales. Al mismo tiempo, se fomentó un clima de interacción y mediación que sirvió para establecer mayores lazos de relación entre todo el estudiantado del aula, una buena forma de estrategia para favorecer un mayor intercambio comunicativo en ELE que ayude a la integración de los alumnos inmigrantes y a la convivencia intercultural.

\section{Conclusiones}

Las actividades realizadas en esta unidad didáctica ayudaron al alumnado de ELE a interiorizar y usar las diversas estructuras de las tipologías textuales trabajadas (descriptiva, expositiva y argumentativa) y a reconocer y usar metáforas. Al mismo tiempo, contribuyeron a la ampliación de vocabulario en diversas categorías gramaticales -principalmente adjetivos-, conocieron los elementos compositivos que conforman al grafiti y reflexionaron sobre el constructo cultural que transmiten estas creaciones. Finalmente, se fomentó a través del dialogo y la reflexión entre estudiantado nativo y extranjero una mirada crítica, coeducativa e integradora.

\section{Bibliografía}

CANALE, M. (1995). «De la competencia comunicativa a la pedagogía comunicativa del lenguaje». En M. Llobera (ed.), Competencia comunicativa. Documentos básicos en la enseñanza de lenguas extranjeras (pp. 63-81). Madrid: Edelsa.

Casado Velarde, M (1998). «Lingüística del texto y marcadores del discurso». En M. A. Martín Zorraquino y E. Montolío Durán (coords.) Los marcadores del discurso: teoría $y$ análisis (pp 55-70). Madrid: Arco Libros.

CASSANY, D. (2005). Expresión escrita en L2/ELE. Madrid: Arco Libros. 
InSTITUTO CERVANTES (2007). Plan curricular del Instituto Cervantes (PCIC). Recuperado el $25 / 5 / 18$, de http://cvc.cervantes.es/Ensenanza/biblioteca_ele/plan_curricular/default.htm. LAKOFF, G. y JOHNSON, M (1998). Metáforas de la vida cotidiana. Madrid: Cátedra LOUREDA LAMAS, O. (2003). Introducción a la tipología textual. Madrid: Arco Libros. Ministerio DE EDUCACIÓN (9/12/2013). Ley Orgánica 8/2013, de 9 de diciembre, para la mejora de la calidad educativa (LOMCE). Recuperado el 25/4/19, de http://www.boe.es/boe/dias/2013/12/10/pdfs/BOE-A-2013-12886.pdf. 


\section{¿Por qué a mí?}

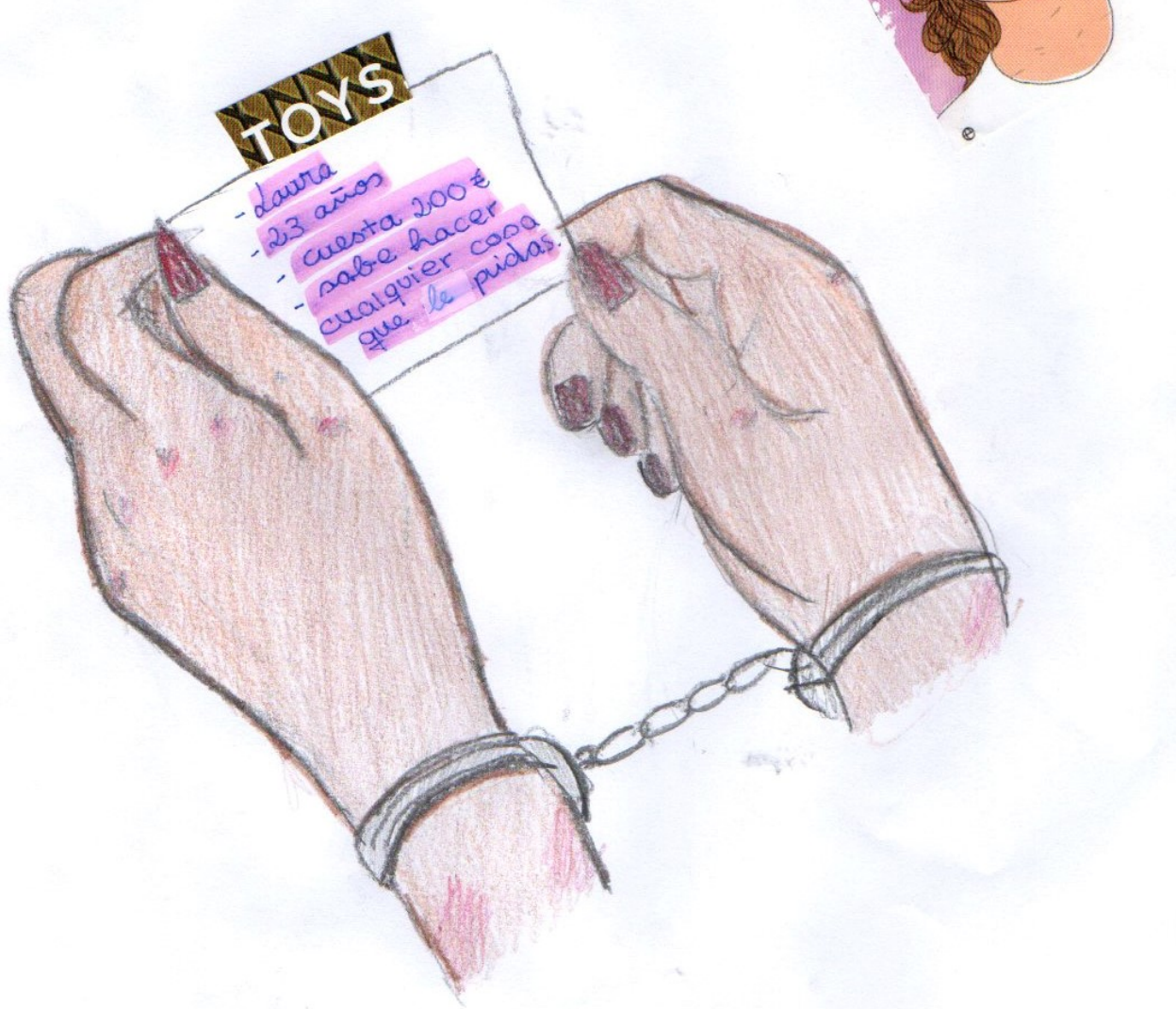

INO Samos abjetos, Sabemos thablation.

por Gllo mos quejatilios? desjadros Eel pazi. 